\title{
Correction to: Pyrethrin from Dalmatian pyrethrum (Tanacetum cinerariifolium (Trevir.) Sch. Bip.): biosynthesis, biological activity, methods of extraction and determination
}

\author{
Nina Jeran • Martina Grdiša (D) Filip Varga - Zlatko Šatović • Zlatko Liber • \\ Dario Dabić $\cdot$ Martina Biošić
}

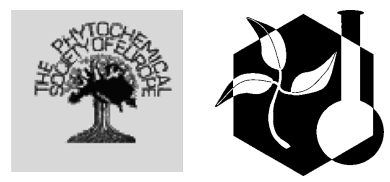

Published online: 1 October 2021

(C) Springer Nature B.V. 2021

Correction to: Phytochem Rev

https://doi.org/10.1007/s11101-020-09724-2

In the original publication, the plant name has been published incorrectly as "Tanacetum cinerariifolium / Trevir./Sch. Bip." in the article title and abstract. The correct name should read as "Tanacetum cinerariifolium (Trevir.) Sch. Bip."

The original article has been corrected.

Publisher's Note Springer Nature remains neutral with regard to jurisdictional claims in published maps and institutional affiliations.

The original article can be found online at https:// doi.org/10.1007/s11101-020-09724-2.

N. Jeran · M. Grdiša $(\bowtie) \cdot$ F. Varga $\cdot$ Z. Šatović

Faculty of Agriculture, Department of Seed Science and Technology, University of Zagreb, Svetošimunska cesta 25, 10000 Zagreb, Croatia

e-mail: mgrdisa@agr.hr

M. Grdiša $\cdot$ F. Varga $\cdot$ Z. Šatović $\cdot$ Z. Liber

Centre of Excellence for Biodiversity and Molecular Plant Breeding (CoE CroP-BioDiv), Svetošimunska cesta 25, 10000 Zagreb, Croatia

Z. Liber

Department of Botany, Division of Biology, Faculty of Science, University of Zagreb, Marulićev trg 9, 10000 Zagreb, Croatia

D. Dabić · M. Biošić

Faculty of Chemical Engineering and Technology, Department of Analytical Chemistry, University of Zagreb, Marulićev trg 19, 10000 Zagreb, Croatia 